University of Warwick institutional repository: http://go.warwick.ac.uk/wrap

This paper is made available online in accordance with publisher policies. Please scroll down to view the document itself. Please refer to the repository record for this item and our policy information available from the repository home page for further information.

To see the final version of this paper please visit the publisher's website. Access to the published version may require a subscription.

Author(s): Cassam, Q.

Article Title: Reply to Duncan Pritchard and John Campbell

Year of publication: 2009

Link to published article : http://dx.doi.org/10.1093/analys/anp044

Publisher statement: This is a pre-copy-editing, author-produced PDF of an article accepted for publication in Analysis following peer review. The definitive publisher-authenticated version, Cassam, Q. (2009). Reply to Duncan Pritchard and John Campbell. Analysis, 69(2), pp. 325-333 is available online at http://dx.doi.org/10.1093/analys/anp044 


\section{Reply to Duncan Pritchard and John Campbell}

\section{Quassim Cassam}

An epistemological how-possible question asks how knowledge, or knowledge of some specific kind, is possible. The main contention of Duncan Pritchard's stimulating comments is that what I call 'explanatory minimalism' appears to offer us just what we are seeking when we ask such a question. This looks like a problem for me given that I defend a version of explanatory anti-minimalism. Pritchard outlines a version of minimalism inspired by the writings of John McDowell and does not find it obvious that this position is lacking in any relevant respect. Nor do I. My minimalism is moderate rather than extreme but Pritchard's objections to anti-minimalism are objections to extreme anti-minimalism. Indeed, his comments do not seem to me to have any direct bearing on what I take to be the fundamental disagreement between minimalism and anti-minimalism.

The issue between minimalism and anti-minimalism is how far we can or need to go in order to tackle a how-possible question. Consider the following familiar example:

$\left(\mathrm{HP}_{\mathrm{ew}}\right)$ How is knowledge of the external world possible?

Philosophers ask this question when they come across factors that make knowledge of the external world look impossible. ${ }^{1}$ Minimalists and anti-minimalists agree that the first step towards providing a satisfying response to $\left(\mathrm{HP}_{\mathrm{ew}}\right)$ is to identify means by which knowledge of the external world is possible. This is Level 1 of a multi-levels response to $\left(\mathrm{HP}_{\mathrm{ew}}\right)$. Next, at Level 2, it needs to be shown that there are no insuperable obstacles to the acquisition of knowledge by the suggested means. Suppose that $\mathrm{P}$ is a representative proposition about the external world and that the proposal under consideration is that it is sometimes possible to know that $\mathrm{P}$ by seeing that $\mathrm{P}$. One worry about this proposal is that one cannot be said to 
see that $\mathrm{P}$ unless one can rule out the hypothesis that one is dreaming and that this is not a hypothesis one can rule out. The same goes for a range of familiar sceptical hypotheses. So if seeing that $\mathrm{P}$ is to be a means of knowing that $\mathrm{P}$ then it either needs to be shown that such hypotheses can be ruled out after all or that being able to rule then out is not necessary for knowing that $\mathrm{P}$ by seeing that $\mathrm{P}$. Either way, minimalists and anti-minimalists are in total agreement about the indispensability of a Level 2 response to $\left(\mathrm{HP}_{\mathrm{ew}}\right)$.

The disagreement between these views only surfaces when we ask what makes it possible for one to know that $\mathrm{P}$ by seeing that $\mathrm{P}$. This is a question about the enabling conditions - background necessary conditions- for epistemic seeing. Anti-minimalists think that there are such conditions and that some of them can be established non-empirically. It is the latter claim with which minimalists disagree. They do not deny the existence of, say, causal enabling conditions for the acquisition of perceptual knowledge but insist that enabling conditions in this sense are not a priori and that there is no need to say anything about them in order to tackle $\left(\mathrm{HP}_{\mathrm{ew}}\right)$. As far as minimalism is concerned we have done everything that can or needs to be done to explain how knowledge of kind $\mathrm{K}$ is possible once we have identified a means $\mathrm{M}$ by which this kind of knowledge is possible and tackled the supposed obstacles to the acquisition of $\mathrm{K}$ by $\mathrm{M}$.

The paradigm anti-minimalist is Kant. In the first Critique he identifies a range of supposedly a priori enabling conditions for the acquisition of perceptual knowledge. These include the capacity to perceive spatially and to think categorially. Spatial perception is the perception of specifically spatial properties such as shape and location. Categorial thinking is thinking by means of categorial concepts such as substance and cause. Kant thinks that the capacity to perceive spatially and to think categorially are a priori enabling conditions 
for the most central cases of knowing that $\mathrm{P}$ by seeing that $\mathrm{P}$. For example, suppose that I know that the cup in my hand is chipped because I can see that it is chipped. I can't see that the cup is chipped without seeing the cup. To see the cup is to perceive an object and Kant thinks that the perception of objects is made possible by the perception of space. To see that the cup is chipped I also need to have the concepts cup and chipped. These are empirical concepts and Kant's contention is that grasp of empirical concepts is made possible by a capacity for categorial thinking.

These claims are already controversial but what is even more controversial is the further suggestion that we have not satisfactorily answered $\left(\mathrm{HP}_{\mathrm{ew}}\right)$ until we have identified such a priori enabling conditions for epistemic perceiving. This is what happens at Level 3 of a multi-levels response to $\left(\mathrm{HP}_{\mathrm{ew}}\right)$. Extreme anti-minimalists think that it is not enough for the purposes of explaining how knowledge is possible to identify means by which it is possible and deal with any obstacles to the acquisition of knowledge by the suggested means. They think that we have not fully explained how knowledge is possible unless we have explained what makes it possible, where explaining what makes it possible is a matter of identifying its a priori enabling conditions. In contrast, moderate anti-minimalists agree that there are a priori enabling conditions for, say, getting knowledge of the external world by means of the senses but see no reason to believe that the uncovering of such conditions is essential for the purposes of answering $\left(\mathrm{HP}_{\mathrm{ew}}\right)$. As far as this version of anti-minimalism is concerned this question has already been satisfactorily answered at Levels 1 and 2.

In his comments Pritchard focuses on the following question: $\left(\mathrm{HP}_{\mathrm{pk}}\right)$ How is perceptual knowledge possible? 
The McDowellian version of minimalism he tentatively recommends grants that sceptical hypotheses are an obstacle to our perceptual knowledge but insists that this obstacle can be overcome. The suggestion is that our perceptual knowledge is not 'problematized' by such hypotheses because in epistemically friendly environments 'the rational support we have for our beliefs actually entails the denials of these sceptical hypotheses' (p. 6). This is a reflection of the fact that our knowledge is supported by factive reasons. So, for example, I know and believe that there is a laptop in front of me because I can see that there is a laptop in front of me, and this entails that there is a laptop in front of me.

From the fact that there is a laptop in front of me it does not follow that I am not dreaming. I could be dreaming that there is a laptop in front of me and wake up to discover that there is a laptop in front of me. In this sense, the factivity of my reasons fails to rule out at least one notorious sceptical hypothesis. To rule out the dreaming hypothesis I would need the premise that I see that there is a laptop in front of me. If I see that there is a laptop in front of me then I know (by seeing) that there is a laptop in front of me and I cannot know in this way that there is a laptop in front of me if I am asleep dreaming. ${ }^{2}$ But for me to know on this basis that I am not dreaming it is not enough that I do in fact see that there is a laptop in front of me. I would also need to know that I see there is a laptop in front of me. ${ }^{3}$ The problem is to account for this kind of self-knowledge. In particular, it needs to be explained how it is possible for me to know that I see that there is a laptop in front of me if I do not already know that I am not dreaming. This is another how-possible question, and insisting on the factivity of our reasons does not make it clear what the answer is.

Suppose, contrary to what I have just been arguing, that Pritchard has managed to overcome the sceptical obstacles to perceptual knowledge that made $\left(\mathrm{HP}_{\mathrm{pk}}\right)$ look pressing in 
the first place. Do we now have an answer to this question? Pritchard supposes that I think more is needed:

In particular, what is required, Cassam argues, is an account of what makes it possible that we are able to acquire the contested knowledge, what Cassam calls the "enabling conditions" for this knowledge. He thus argues for a response to "how possible" questions that functions on an additional third level (p. 4).

This is not how I see things. Since I am a moderate anti-minimalist the only sense in which I argue for a response to $\left(\mathrm{HP}_{\mathrm{pk}}\right)$ that functions on an additional third level is that $\mathrm{I}$ argue for the possibility of a Level 3 response. I do not argue for the necessity of such a response. ${ }^{4}$ It is only the extreme anti-minimalist who thinks that a Level 3 response is, as Pritchard puts it, 'required'. When Pritchard goes on to suggest that a response to $\left(\mathrm{HP}_{\mathrm{pk}}\right)$ that only goes as far as Level 2 might be sufficient he is not saying anything with which the moderate antiminimalist would disagree. There would be a disagreement if Pritchard were denying the existence of a priori enabling conditions for knowing by perceiving but this is not an issue he takes up in his comments.

Pritchard shows that there is more than one way of understanding the distinction between minimalism and anti-minimalism. If the latter is the view that an account of the $\underline{a}$ priori enabling conditions of perceptual knowledge is necessary for the purposes of answering $\left(\mathrm{HP}_{\mathrm{pk}}\right)$ and former is the denial that such an account is necessary then what I call 'moderate anti-minimalism' is really a version of minimalism. I see it as a form of antiminimalism because I take the fundamental disagreement to be over whether there are genuinely a priori enabling conditions of perceptual knowledge. Anti-minimalists, whether moderate or extreme, think there are. Minimalists think there aren't. ${ }^{5}$ Pritchard understands 
the dispute between minimalism and anti-minimalism in the first way. I understand it in the second.

It is worth adding, perhaps, that on my conception of minimalism there is no reason to count McDowell as a minimalist. Far from denying that a Level 3 account of perceptual knowledge is possible he gives just such an account in his Woodbridge Lectures. He claims that we can only make sense of objects coming into view in perception or 'intuition' because we can see how they fit into a 'view of the world', and that seeing how objects fit into a view of the world depends on 'something like the categories, and the principles Kant connects with them' (1998b: 465-6). In my terms, this amounts to the claim that categorial thinking is an enabling condition for object perception and therefore also for perceptual knowledge of objects. McDowell would come out as a minimalist only if he thinks that it is an empirical question whether categorial thinking is an enabling condition for perceptual knowledge. It seems unlikely that this is what he thinks.

The merits, or otherwise, of moderate anti-minimalism are difficult to decide in the abstract. There is no substitute for looking in detail at the arguments I present in support of (a) the claim that spatial perception and categorial thinking are a priori enabling conditions for perceptual knowledge and (b) the denial that the identification of such conditions is necessary for the purposes of answering $\left(\mathrm{HP}_{\mathrm{pk}}\right)$. The Spatial Perception Requirement (SPR) is the focus of John Campbell's intriguing and illuminating paper. SPR states that in order to perceive that something is the case and thereby know that it is the case one must be capable of spatial perception. To perceive that something is the case is to perceive epistemically. The capacity to perceive spatially is the capacity to perceive space or spatial properties such as shape and location. As Campbell notes, it is possible to perceive that 
something is the case without perceiving an object but I take it that there is something basic about cases in which one's perceiving that something is the case depends on perception of an object. These are cases of what I call primary epistemic perceiving, ones in which I perceive that a material object $\mathrm{b}$ is $\mathrm{P}$ by perceiving $\mathrm{b}$ itself. Is it plausible, then, that $\mathrm{a}$ capacity for spatial perception is necessary for primary epistemic perceiving?

I discuss two arguments for SPR, an indirect and a direct argument. Both attempt to establish a link between object perception and spatial perception. The direct argument starts off by saying that it is not possible to perceive a material object without perceiving any of its spatial properties or without perceiving space. The indirect argument, which many commentators attribute to Kant, says that it isn't possible to perceive an object without differentiating it perceptually from other objects in its environment, and that perceptual object differentiation requires the perception of space or spatial properties. ${ }^{6}$ I reject the indirect argument in favour of a version of the direct argument. Campbell argues that the direct argument depends on the indirect argument and that the latter is better than my discussion suggests. This is the basis on which he agrees with me that 'perception of a material object rests on one's having the capacity for spatial perception' (p. 15).

It might seem obvious that object perception requires spatial perception as long as we focus on sight and touch. Material objects have spatial properties and it is hard to make sense of the idea that one could see or touch such an object without perceiving any of its spatial properties. When I see the laptop in front of me I see its shape and location. When I touch it I encounter its solidity. The problem for the direct argument is that sight and touch are not the only senses that give us perceptual access to objects. Hearing and smell also need to be taken into account. When I hear the drunk shouting outside my apartment every 
night I hear him, and not just the sounds that he makes. Yet drunks are material objects. It is true that I hear the drunk as being somewhere so spatial awareness is still involved. But what if I have lost the capacity for auditory localization? Assuming, not uncontroversially, that this would not necessarily prevent me from hearing the drunk it looks as though the direct argument is in trouble. If a being with no sight or touch and no auditory localization can still hear objects it is false that object perception requires spatial perception.

In response, I argue in my book that the ability to hear material objects is parasitic upon the ability to perceive their primary or spatial properties by sight or touch. Material objects can only be heard because their size, shape and solidity can be seen or felt, and this means that a being with non-spatial hearing but no vision or touch would not be capable of perceiving material objects. Such a being might be capable of hearing sounds but sounds are not material objects. Campbell's initial response to these claims is this:

Suppose, now, that we have someone born only with hearing, no other senses. This person faces formidable difficulties in coming to anything like our ordinary understanding of the world, but is it obvious that the difficulties are in principle insuperable? This person has to formulate the hypothesis that there are such things as spatially related objects, for example bells and people, without information from vision or touch, and conjecture that these things are causing some of the sounds she hears. Suppose it is possible for this person to formulate hypotheses to the effect that there are various types of material objects and that they are responsible for the sounds she hears. Is there some difficulty about saying that this person hears material objects? After all, that is how she would report her perceptions.... But then the full modal force of the Spatial Perception Requirement cannot be sustained. 
One question about this conjecture is whether, even if someone born only with hearing could form the hypothesis that the sounds she hears are caused by material objects, it would be correct to say that she hears those objects. Consider the following analogy: Crusoe sees footprints in the sand and forms the hypothesis that another person is responsible for them. There is little inclination in this case to say that Crusoe sees that other person by seeing the footprints for which he is responsible. Why should we be any more inclined to say that the Campbell's subject hears objects by hearing the sounds they make, given that those objects are not accessible to her in any other way? The natural thought here is that the subject's access to objects is inferential rather than perceptual. She conceives of material objects but does not perceive them.

Campbell's response to his conjecture is to argue while that a subject born with no sight or touch might have the idea of the world as constituted by a complex of dispositions what she would lack is a conception of the categorical objects that have those dispositions. This seems right, as does the closely related suggestion that spatial perception is required for knowledge of the categorical objects and properties that cause the sounds we hear. So Campbell agrees with me that our capacity to hear material objects is parasitic on our possession of other, spatial, senses such as sight or touch. The question he goes on to raise is what the dependence of non-spatial perception of material objects on spatial perception of material objects comes to. He gives the example of a person hearing a bell, and writes that 'the natural proposal is that to be hearing the bell itself, as opposed to merely the sound made by the bell, one must be capable of recognizing that very bell when one encounters it in spatial perception' (p.11). This is the basis of his idea that the direct argument for SPR depends on the indirect argument. 
The latter has two premises:

(1) Perception of an object requires that one differentiate it perceptually from its surroundings.

(2) Perceptually differentiating an object from its surroundings requires that one have the capacity for spatial perception.

I say that (1) can't be right because it is possible to touch and, in this sense, perceive a brick in a wall without differentiating it from its surroundings. Campbell points out, in response, that for my purposes perceiving an object $\mathrm{X}$ 'should be correlative with being able to grasp a proposition "that is F", which refers demonstratively to $\mathrm{X}$ and which is the content of one's perceptual knowledge about X' (p. 13). Merely touching a brick is not enough for one to be able to think about it. What is needed if one's perception of an object is to be the basis of one's epistemic perception that it is thus and so, is, precisely as (1) claims, perceptual differentiation of the object.

All of this is entirely plausible but there is still a question about (2). For when I hear two people arguing through a wall I can differentiate them perceptually without having any perception of their shapes or locations. Doesn't this show that (2) is false? It is not just that some kind of non-spatial auditory differentiation is possible but that the differentiation that is possible in such cases is 'sufficient to ground the use of a demonstrative referring to the object' (p. 14). Why, in that case, does Campbell still like the indirect argument? Because the conclusion of his version of the direct argument is still in play: non-spatial perception of a material object requires the capacity to recognize when one has encountered that very object in perception, and this means that the perceptual differentiation of an object must be sufficient for one to be able to recognize it as the same object when one encounters it in a 
spatial sense-modality. That is why perception of a material object rests on one's having the capacity for spatial perception.

It is not at all obvious that this amounts to a demonstration of the dependence of the direct on the indirect argument. If anything, Campbell's discussion suggests the opposite. If I can hear two people as distinct without perceiving their shapes or locations then, contrary to what the indirect argument suggests, SPR cannot be established simply by thinking about what is needed for perceptual differentiation. On the other hand, in order to hear two people or objects as distinct I must hear them, and I do not count as hearing them unless I can recognize them when I encounter them in spatial perception. But this is just the conclusion of the direct argument. On this account it is the latter that is doing all the work. Perceptual differentiation of an object must be sufficient for one to be able to recognize it as the same object when one encounters it in spatial perception because possession of this recognitional ability is, as the direct argument says, necessary for hearing an object in the first place.

No doubt it would be a mistake to make too much of this. Instead of insisting on the priority of one or other argument perhaps it would be best to view the direct and indirect arguments as two aspects or dimensions of one complex argument for SPR. The substantive question is whether the central claim of what I have referred to as Campbell's version of the direct argument is correct. Imagine the following scenario: Lord Peter is standing a short distance from a church with eight bells in its tower. One of the bells, Tailor John, is tolling, while the others are silent. Can Lord Peter hear Tailor John? Yes. His hearing is good and he is not too far away. Moments later, all the bells are silent and Lord Peter is in the church tower looking at the bells. Can he recognize the bell that was tolling moments before? If he isn't a bell ringer perhaps he would be hard pushed to say which particular bell he heard but 
it is not correct to conclude that what he was hearing previously were only the sounds made by Tailor John and not Tailor John. This implies that Campbell's requirement is too strong. It is implausible that to be hearing Tailor John itself one must be capable of recognizing that very bell when one encounters it in spatial perception.

One of the recurring themes of my chapter on spatial perception is that Kantian and standard neo-Kantian arguments in support of SPR fail because they concentrate on sight and touch and forget that these are not the only modes of perceptual access to material objects. Unless one is prepared to deny that material objects can literally be heard or to insist that auditory perception is necessarily spatial it is going to be difficult to maintain that object perception requires a capacity for spatial perception. To this extent, at least, it is possible to sympathize with minimalism. The Level 3 conditions for perceptual knowledge that Kant tries to establish are highly general and a priori. As I see it, the hard question for Kant is not whether his conditions can be established non-empirically but whether they can be established at all. ${ }^{7}$ 


\section{References}

Allison, H. (1983), Kant's Transcendental Idealism: An Interpretation and Defense (New Haven: Yale University Press).

Cassam, Q. (2007), The Possibility of Knowledge (Oxford: Oxford University Press).

McDowell, J. (1998a), 'Singular Thought and the Extent of Inner Space', in Meaning,

Knowledge and Reality (Cambridge, Mass.: Harvard University Press).

McDowell, J. (1998b), 'Having the World in View: Sellars, Kant, and Intentionality', Journal of Philosophy, 95.

Stroud, B. (2000), 'Scepticism and the Possibility of Knowledge', in Understanding Human Knowledge (Oxford: Oxford University Press).

Warren, D. (1998), 'Kant and the A Priority of Space', Philosophical Review, 80. 
${ }^{1}$ See, for example, Stroud 2000.

${ }^{2}$ This appears to be McDowell's argument in the following passage: 'one's knowledge that one is not dreaming in the relevant situation owes its credentials as knowledge to the fact that one's senses are yielding one knowledge of the environment - something that does not happen when one is dreaming' (1998a: 238).

${ }^{3}$ Tim Williamson made this point in response to a draft of the first chapter of The Possibility of Knowledge.

${ }^{4}$ See Cassam 2007: 46-50.

${ }^{5}$ If naturalism is the view that there is no a priori knowledge then minimalists tend to be naturalists. See Cassam 2007: 38 on the alliance between naturalism and minimalism. This is an aspect of minimalism that doesn't figure in Pritchard's discussion.

${ }^{6}$ Henry Allison reads Kant's Transcendental Aesthetic in this way. See Allison 1983, chapter 5. Warren 1998 demonstrates that the indirect argument is not Kant's argument in the Aesthetic.

${ }^{7}$ Thanks to Ciara Fairley for helpful comments and discussion. 